\title{
Debunking the granular origins of aggregate fluctuations: from real business cycles back to Keynes
}

\author{
Giovanni Dosi ${ }^{1} \cdot$ Mauro Napoletano $0^{1,2,3,4} \cdot$ Andrea Roventini ${ }^{1,2}$. \\ Tania Treibich ${ }^{1,2,5}$ (D)
}

Published online: 5 October 2018

(C) The Author(s) 2018

\begin{abstract}
In this work we study the granular origins of business cycles and their possible underlying drivers. As shown by Gabaix (Econometrica 79:733-772, 2011), the skewed nature of firm size distributions implies that idiosyncratic (and independent) firm-level shocks may account for a significant portion of aggregate volatility. Yet, we question the original view grounded on "supply granularity", as proxied by productivity growth shocks - in line with the Real Business Cycle framework-, and we provide empirical evidence of a "demand granularity", based on investment growth shocks instead. The role of demand in explaining aggregate fluctuations is further corroborated by means of a macroeconomic Agent-Based Model of the "Schumpeter meeting Keynes" family Dosi et al. (J Econ Dyn Control 52:166-189, 2015). Indeed, the investigation of the possible microfoundation of RBC has led us to the identification of a sort of microfounded Keynesian multiplier.
\end{abstract}

Keywords Business cycles · Granular residual · Granularity hypothesis · Agent-based models · Firm dynamics · Productivity growth · Investment growth

JEL Classification C63 $\cdot \mathrm{E} 12 \cdot \mathrm{E} 22 \cdot \mathrm{E} 32 \cdot \mathrm{O} 4$

The authors gratefully acknowledge the financial support of the Horizon 2020 Framework Program of the European Union under grant agreement no 649186, ISIGrowth (Innovation-Fuelled, Sustainable, Inclusive Growth).

Tania Treibich

t.treibich@maastrichtuniversity.nl

1 Institute of Economics (LEM), Scuola Superiore Sant'Anna, Pisa, Italy

2 Observatoire Français des Conjonctures Economiques (OFCE), Sophia-Antipolis, France

3 SKEMA Business School, Sophia-Antipolis, France

4 Université Côte d'Azur, Sophia-Antipolis, France

5 Maastricht University, Maastricht, The Netherlands 


\section{Introduction}

Every economy is composed by a multitude of heterogeneous, interacting firms. And such firms are not of similar size but their size distributions are skewed and fattailed (see e.g. Axtell, 2001). These are two quite obvious and very robust stylized facts. And more in general, since the pioneering works of Gibrat (1931) and Ijiri and Simon (1977), a vast amount of empirical research has been devoted to identify robust statistical regularities concerning the cross-sectional dynamics of firms (see Dosi, 2007 for a recent account of this literature). Yet, until the seminal work of Gabaix (2011) their implications in terms of properties of the aggregate time series went largely unexplored.

In particular, as Gabaix (2011) shows, idiosyncratic (and independent) firm-level shocks may account for a significant portion of aggregate volatility: when firms are Zipf-law distributed, the latter decays according to $\frac{1}{\ln N}$, with $\mathrm{N}$ the number of firms, rather than $\frac{1}{\sqrt{N}}$ as in the case of normally distributed firms, so that shocks on big firms "carry on" to the aggregate. Hence, the "granular" interpretation of fluctuations. ${ }^{1}$ This view also reconciles the analysis of business cycles with the historical evidence about major recessions, that points to the high relevance of microeconomic triggers.

This is a theorem and an important one. If the firm size distribution follows a Zipf's law, then the theorem holds and the granularity result too. The question we raise is whether the nature of the shocks matters in terms of their impact on aggregate dynamics. In the theory's proposed application, Gabaix uses productivity growth shocks, as a "microfoundation for the aggregate shocks of real business cycle models" (Gabaix, 2011, p. 735). His positive result on US data would therefore posit that individual shocks to firms should substitute the usual aggregate productivity shocks as the source of fluctuations, yet keeping the core of the theory (i.e. the link between productivity shocks and economic growth) intact. This alerted our curiosity. How come that such an ill-grounded and far-fetched theory, which fares quite poorly on the aggregate could perform well in its "granular" version? So, we went back to the COMPUSTAT data on US firms and tried to re-do the calculations. Basically, what we found is that the results rest on three methodological assumptions, namely that i) the "residual" is based on a normalization on the average of the top firms and not on the whole sample; ii) no demand shocks are considered; and iii) the micro data are subject to important "winsorizing", that is, outliers are eliminated. If all three assumptions are dropped, the model loses significance and its explanatory power dramatically drops. There is an interesting paradox here: granular productivity shocks appear to be important only if one basically assumes that shocks themselves are not fat-tailed. If they are allowed to be - as the empirical literature robustly suggests (cf. Bottazzi and Secchi 2003a; Castaldi and Dosi 2009; Dosi 2007), granularity

\footnotetext{
${ }^{1}$ The work of Gabaix has also triggered a growing literature on the role played by large firms not only for business fluctuations but also in international trade. The list of works belonging to these streams of research include (Di Giovanni et al. 2014; Di Giovanni and Levchenko 2012; Di Giovanni et al. 2011; Carvalho and Grassi 2015; Clementi and Palazzo 2016; Bottazzi et al. 2017; Arroyo and Alfarano 2017).
} 
in supply loses importance. ${ }^{2}$ Conversely, we experimented with demand shocks, proxied by investment growth. Demand granularity is there and is important in accounting for fluctuations in aggregate GDP growth.

Next, we repeated the experiments in an Agent-Based Model ${ }^{3}$ of the "Schumpeter meeting Keynes" family (cf. Dosi et al. 2010, 2013, 2015, 2017b). We first study the emergence of the main statistical features of firm dynamics. We find that the model can jointly account for many firm- and industry-levels stylized facts, including power-law distributed firm sizes (with exponent 1), in line with the assumptions associated with the granularity hypothesis. Then we compare the empirical results with those obtained by running the same regressions on the artificial data generated by our model. The results using the simulated data are strikingly similar: no sign of "supply granularity" and corroborating evidence of a "demand granularity". Putting it another way: the search for the possible RBC interpretation of the granularity hypothesis led us to the identification of a Keynesian explanation, hinting to the existence of a sort of microfounded Keynesian multiplier.

The rest of the paper is structured as follows. Section 2 analyzes the granular properties of business fluctuations on empirical data. Section 3 describes the model. Finally, Section 4 analyzes the ability of our model to reproduce the main stylized facts of firm dynamics, and tests the granular properties of business fluctuations on simulated data. Finally, Section 5 concludes.

\section{The granular hypothesis: an empirical assessment}

The granular hypothesis states that idiosyncratic firm-level shocks to the largest firms in the economy have a significant impact on aggregate fluctuations (Gabaix 2011). It is important to note that the theory is agnostic about the type of shocks which should matter (Gabaix writes that "This paper conceptualizes these shocks as productivity growth, but the analysis holds for other shocks", p. 735). Yet, the granularity variable used in the empirical validation was chosen so as to provide a microfoundation of the RBC models, rather than as a repeal of a modelling approach focused on aggregate exogenous shocks (in Gabaix' words "the granular hypothesis offers a microfoundation for the aggregate shocks of real business cycle models", p. 735). We label this approach "supply granularity", and we question whether other types of shocks, in particular those, such as investment ones, more related to demand variations, would have a larger impact on GDP dynamics.

In what follows we focus on the empirical evaluation of the hypothesis, using data on US listed firms from the COMPUSTAT database. Gabaix (2011) found that the labour productivity growth shocks to the largest 100 firms in the United States would explain one third of the variations in GDP per capita growth $\left(R^{2}=0.38\right.$, cf.

\footnotetext{
${ }^{2}$ Note that output growth-rate distributions are well proxied by double-exponential densities suggesting that mild fluctuations coexist with deep dowturns (Fagiolo et al. 2008). Both RBC and New Keynesian models are not able to account for these statistical properties as showed in Ascari et al. (2015).

${ }^{3}$ See Fagiolo and Roventini $(2012,2017)$ for surveys of macroeconomic Agent-Based Models.
} 
Table 1 of the original paper, second column). We test the robustness of the results to a range of specifications of the empirical model and to changes in the computation of the main variables. Further, we propose the use of an alternative variable - i.e. investment growth - defining the firm-level shocks, and we compare the results to productivity growth shocks.

\subsection{Methodology, data and variables}

The granular residual represents the sum of idiosyncratic shocks to the largest firms in an economy, weighted by size. In line with the theoretical proof by Gabaix (2011), if the firm size distribution is fat-tailed (Pareto-distributed), idiosyncratic shocks to the largest firms should not "evaporate" or "average out" at the aggregate level, but should affect GDP dynamics.

Similar to Gabaix (2011), in each year between 1951 and 2008, we consider the K firms with the largest total sales, and we compute the residual according to: ${ }^{4}$

$$
\Gamma_{L P, K}(t)=\sum_{i \in K} \frac{S_{i}(t-1)}{Y(t-1)}\left(g_{L P, i}(t)-\bar{g}_{L P}(t)\right),
$$

where $\Gamma_{L P, K}$ is the granular residual based on productivity growth, $L P$ stands for labour productivity, $K$ indicates the number of top firms over which the granular measure is computed. The ratio $\frac{S_{i}}{Y}$ measures the share of firm $i$ 's sales in GDP. Finally, the idiosyncratic shock to firm $i$ is measured as $g_{L P, i}(t)-\bar{g}(t)$, that is, the growth rate of labour productivity of firm $i$, depurated by the mean growth rate of the largest $\mathrm{Q}$ firms.

The impact of the granular residual on aggregate fluctuations is measured by regressing the GDP per capita growth rate on the current and past residuals, and assessing the total explained variance via the $R^{2}$ statistics:

$$
g_{G D P / c a p .}(t)=\beta_{0}+\beta_{1} \Gamma_{L P}(t)+\beta_{2} \Gamma_{L P}(t-1)+\beta_{3} \Gamma_{L P}(t-2)+\epsilon_{1}(t)
$$

Such model specification (defined as Model 1 from now on) entails a series of issues:

1. Dependent variable: The use of GDP per capita growth is common in the long run growth literature, as it measures changes in the development level. However, the granular hypothesis discusses the role of firm shocks on the business cycle. The results should then be tested also using GDP growth as the dependent variable.

2. Serial correlation: We include GDP growth lags to control for possible serial correlation in the residuals.

The foregoing issues lead to two alternative model specifications (Models 2 and 3 respectively):

$$
\begin{aligned}
g_{G D P / \text { cap. }}(t)= & \beta_{0}+\beta_{1} \Gamma_{L P}(t)+\beta_{2} \Gamma_{L P}(t-1)+\beta_{3} \Gamma_{L P}(t-2) \\
& +\gamma_{1} g_{G D P}(t-1)+\gamma_{2} g_{G D P}(t-2)+\epsilon_{2}(t) \\
g_{G D P}(t)= & \beta_{0}+\beta_{1} \Gamma_{L P}(t)+\beta_{2} \Gamma_{L P}(t-1)+\beta_{3} \Gamma_{L P}(t-2) \\
& +\gamma_{1} g_{G D P}(t-1)+\gamma_{2} g_{G D P}(t-2)+\epsilon_{2}(t)
\end{aligned}
$$

\footnotetext{
${ }^{4}$ Equation 1 mirrors equation 33 displayed in p. 750 of Gabaix (2011).
} 
Table 1 Regressions on U.S. COMPUSTAT data, 1951-2008

\begin{tabular}{|c|c|c|c|c|c|}
\hline \multirow{4}{*}{ Dep. var: } & \multicolumn{5}{|c|}{ Productivity growth residuals } \\
\hline & \multirow{2}{*}{$\frac{\text { GDP per capita growth }}{\text { Winsorizing data }}$} & \multicolumn{4}{|c|}{ GDP growth } \\
\hline & & & & Not winso & ng data \\
\hline & (1) & $(2)$ & (3) & (4) & $(5)$ \\
\hline constant & $\begin{array}{l}0.017 * * * \\
(0.002)\end{array}$ & $\begin{array}{l}0.028 * * * \\
(0.002)\end{array}$ & $\begin{array}{l}0.026^{* * *} \\
(0.006)\end{array}$ & $\begin{array}{l}0.029 * * * \\
(0.007)\end{array}$ & $\begin{array}{l}0.031 * * * \\
(0.007)\end{array}$ \\
\hline$\Gamma_{L P}(t)$ & $\begin{array}{l}2.611 * * * \\
(0.669)\end{array}$ & $\begin{array}{l}2.701 * * * \\
(0.659)\end{array}$ & $\begin{array}{l}2.622 * * * \\
(0.706)\end{array}$ & $\begin{array}{l}0.608 * * * \\
(0.207)\end{array}$ & $\begin{array}{l}0.147 \\
(0.138)\end{array}$ \\
\hline$\Gamma_{L P}(t-1)$ & $\begin{array}{l}2.882 * * * \\
(0.654)\end{array}$ & $\begin{array}{l}2.905 * * * \\
(0.644)\end{array}$ & $\begin{array}{l}3.316^{* * * *} \\
(0.783)\end{array}$ & $\begin{array}{l}0.073 \\
(0.222)\end{array}$ & $\begin{array}{l}0.057 \\
(0.136)\end{array}$ \\
\hline$\Gamma_{L P}(t-2)$ & $\begin{array}{l}2.139 * * * \\
(0.654)\end{array}$ & $\begin{array}{l}2.172 * * * \\
(0.0 .680)\end{array}$ & $\begin{array}{l}2.108^{* * *} \\
(0.748)\end{array}$ & $\begin{array}{l}0.157 \\
(0.207)\end{array}$ & $\begin{array}{l}0.109 \\
(0.125)\end{array}$ \\
\hline$g_{G D P}(t-1)$ & & & $\begin{array}{l}-0.050 \\
(0.137)\end{array}$ & $\begin{array}{l}0.166 \\
(0.150)\end{array}$ & $\begin{array}{l}0.107 \\
(0.161)\end{array}$ \\
\hline$g_{G D P}(t-2)$ & & & $\begin{array}{l}0.123 \\
(0.131)\end{array}$ & $\begin{array}{l}-0.113 \\
(0.149)\end{array}$ & $\begin{array}{l}-0.095 \\
(0.161)\end{array}$ \\
\hline $\mathrm{N}$ & 55 & 55 & 55 & 55 & 55 \\
\hline$R^{2}$ & 0.400 & 0.416 & 0.428 & 0.171 & 0.066 \\
\hline
\end{tabular}

Cols. 1-3: Gabaix’ residual, alternative model specifications; Col. 4: our computed residual, not winsorizing data. Col 5: our computed residual, not winsorizing data, normalization on all sample. Standard errors in parentheses. *: significant at $10 \%$ level; **:significant at $5 \%$ level; ***:significant at $1 \%$ level

3. Shocks: Although firm-level shocks at the source of aggregate fluctuations are a generic term according to the theory, at the empirical level they are identified using labour productivity growth, computed as the log difference of the ratio of real sales ${ }^{5}$ per number of employees. Note that the choice of productivity as the "granular variable" can be directly related to Real Business Cycle (RBC) explanation of business cycles, as also stated by Gabaix. Indeed, this choice entails a specific supply-sided view on the sources of aggregate fluctuations. Instead, we also explore the relevance of the demand-side by considering investment growth shocks.

4. Normalization range: The original analysis is set by defining the group of top firms as the largest 100 in terms of size in the previous period $(\mathrm{K}=100)$. In addition, the average growth rate of labour productivity (which is the benchmark against which the intensity of the idiosyncratic shock is measured) is also computed within the same group of top firms $(\mathrm{Q}=100) .{ }^{6}$ We think that this is atds with the granular hypothesis, which links the impact of firm-level shocks, i.e.

\footnotetext{
${ }^{5}$ Real sales are obtained dividing nominal ones by the GDP deflator. Note that in Gabaix (2011) it is not clear whether or how sales are deflated.

${ }^{6}$ In the main specification of Gabaix, $Q=K=100$; but he also experiments with $Q=1000$.
} 
how well or badly a firm performs, to the performance of the general economy. We therefore propose to evaluate idiosyncratic shocks with respect to the whole firm sample average instead.

5. Data cleaning: Extreme values and outliers are removed from the firm sample by winsorizing the data at a $20 \% .^{7}$ We show below the distributions of productivity growth and investment growth and the location of the 20th and 80th percentiles (see Fig. 1). They reveal that such procedure is quite extreme: for instance in firm-level studies, it is common to clean the data by removing observations below the 1 st or above the 99th percentiles. In addition, extreme values in terms of growth rates are linked to (small) firm size: information about large firms (especially here, listed firms) is more accurate and does not suffer from large "jumps". Finally, there is an interesting paradox here: how can we assess the importance of granular shocks when the shocks themselves are not fat-tailed? In what follows, we compare the results with or without such cleaning procedure.

In line with Gabaix (2011), we use the data from COMPUSTAT which includes the largest firms listed on the US stock exchange for the years 1951-2008. All sectors of activity are considered, except oil, energy and finance. Data on GDP (nominal GDP, GDP deflator and real GDP per capita) are obtained from the U.S. Bureau of Economic Analysis. To validate the data, we compare the aggregate statistics in our sample to those of Gabaix. As shown in Fig. 2, the largest 100 firms in our sample account for around 30\% of total GDP, mirroring Fig. 1 in (Gabaix 2011).

\subsection{Empirical results}

We run a battery of "granularity" regressions following the discussion in the previous section. The results are presented in Tables 1 and 2.

Let us begin with the regressions considering productivity growth shocks. The first three columns of Table 1 consider Models 1 to 3 respectively, using the granularity residual data as provided on Gabaix's website. ${ }^{8}$ The fourth and fifth columns consider Model 3, with alternative specifications for the computation of the granular residual. Results in the first three columns are very similar to the the original ones, showing that the findings of Gabaix are robust to changes in the model specification, i.e. using GDP growth as the dependent variable instead of GDP per capita growth, and adding the lagged GDP growth controls. Instead, when the data are not winsorized, i.e. when we do not impose the drastic cleaning procedure of Gabaix, the significance and explanatory power of the granular residual is considerably reduced (the $R^{2}$ falls from 0.43 to 0.17 , cf. columns 3 vs. 4 of Table 1 ). Further, in the most general specification (column 5 of Table 1), when firm data are not winsorized and are normalized on the whole sample, the granular residual is no longer significant, and the $R^{2}$ further collapses to 0.07 . These results contrast with the granularity hypothesis, as the largest

\footnotetext{
${ }^{7}$ More precisely, all observations below the second decile of the productivity growth distribution are set equal to the value of the second decile. Similarly, all observations above the 8 th decile are set equal to the value of the 8 th decile.

${ }^{8}$ https://scholar.harvard.edu/files/xgabaix/files/granular_origins_data.pdf.
} 

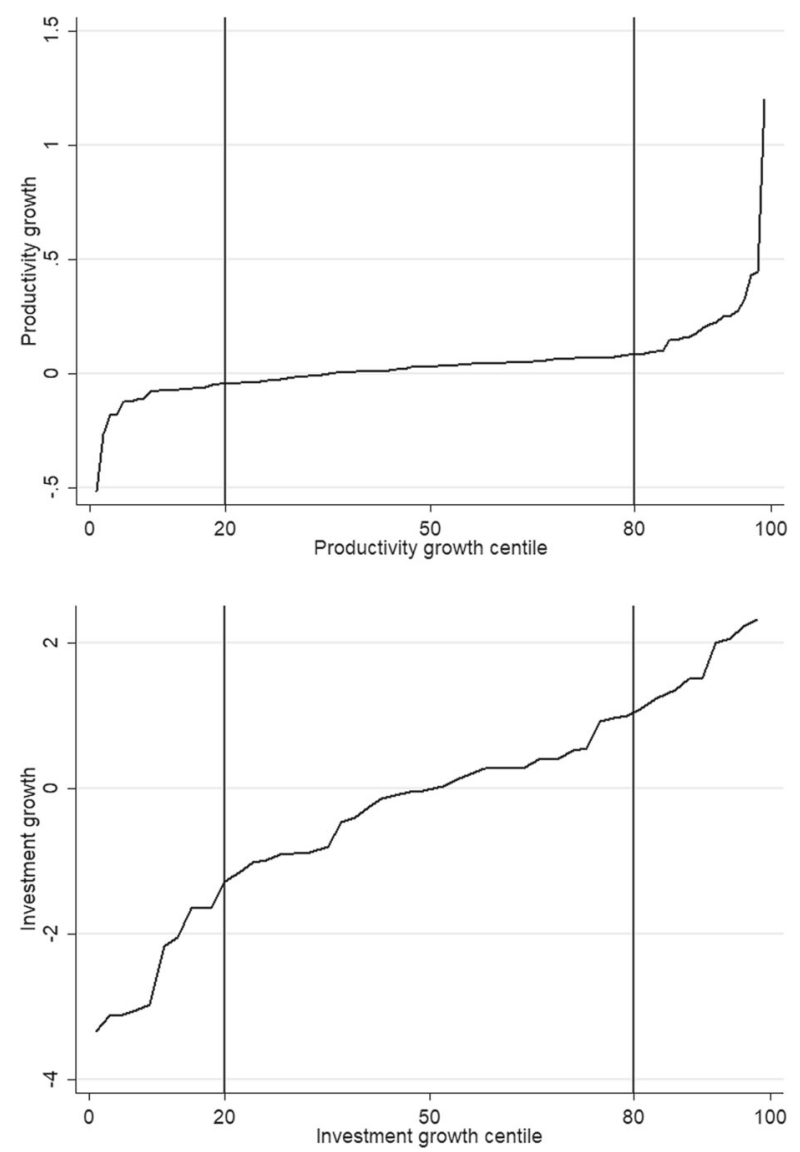

Fig. 1 Percentiles of the distribution of productivity growth (top) and investment growth (bottom) in 2008 in the COMPUSTAT database. Vertical lines show the 20th and 80th percentiles, which are the levels at which winsorizing of the data is done

positive and negative shocks should be amplified and increase the link between the residual and GDP growth.

We now perform the same regressions employing the investment growth residual (cf. Table 2). We find that the "demand-granularity" hypothesis is confirmed in our preferred specifications (columns 2 and 3): the investment growth granular residual has a positive impact on GDP growth. However, the overall explanatory power of the granular residual remains much lower than in Gabaix's analysis (0.18 against 0.38). ${ }^{9}$

Our results suggest that the empirical evidence in favor of the granular hypothesis is much less strong than what was found in Gabaix (2011). Moreover, in our preferred and most general specifications (column 5 in Table 1 and column 3 in Table 2), the investment growth granular residuals have a higher explanatory power

\footnotetext{
${ }^{9}$ When both residuals are included in the regression jointly, the results do not change.
} 


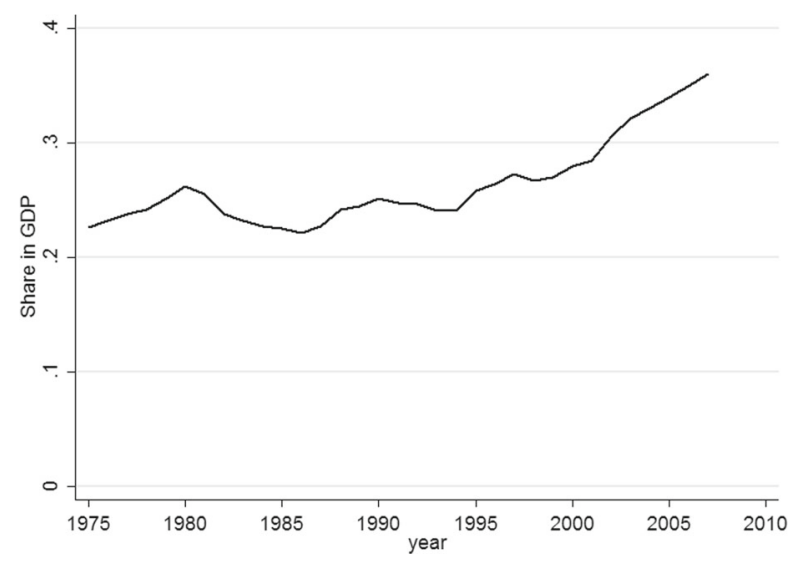

Fig. 2 Sum of the sales of the top 100 firms as a fraction of GDP, final sample

than productivity-driven ones. Such results militate in favor of the idea that Keynesian, demand-driven granular shocks play a more important role in explaining the granular origins of aggregate fluctuations than supply-side productivity ones.

Table 2 Regressions on U.S. COMPUSTAT data, 1951-2008

\begin{tabular}{|c|c|c|c|}
\hline \multirow{4}{*}{ Dep. var: } & \multirow{2}{*}{\multicolumn{3}{|c|}{$\begin{array}{l}\text { Investment growth residuals } \\
\text { GDP growth }\end{array}$}} \\
\hline & & & \\
\hline & \multirow{2}{*}{$\begin{array}{l}\text { Winsorizing data } \\
\text { (1) }\end{array}$} & \multicolumn{2}{|c|}{ Not winsorizing data } \\
\hline & & (2) & (3) \\
\hline \multirow[t]{2}{*}{ constant } & $0.034 * * *$ & $0.035^{* *}$ & $0.043 * * *$ \\
\hline & $(0.008)$ & $(0.009)$ & $(0.011)$ \\
\hline \multirow[t]{2}{*}{$\Gamma_{I}(t)$} & 0.017 & $0.014^{*}$ & $0.017 * * *$ \\
\hline & $(0.015)$ & $(0.007)$ & $(0.006)$ \\
\hline \multirow[t]{2}{*}{$\Gamma_{I}(t-1)$} & 0.008 & 0.004 & 0.006 \\
\hline & $(0.016)$ & $(0.008)$ & $(0.007)$ \\
\hline \multirow[t]{2}{*}{$\Gamma_{I}(t-2)$} & -0.008 & -0.006 & -0.005 \\
\hline & $(0.015)$ & $(0.008)$ & $(0.006)$ \\
\hline \multirow[t]{2}{*}{$g_{G D P}(t-1)$} & 0.027 & 0.012 & -0.110 \\
\hline & $(0.148)$ & $(0.148)$ & $(0.156)$ \\
\hline \multirow[t]{2}{*}{$g_{G D P}(t-2)$} & -0.064 & -0.083 & -0.082 \\
\hline & $(0.147)$ & $(0.151)$ & $(0.155)$ \\
\hline $\mathrm{N}$ & 55 & 55 & 55 \\
\hline$R^{2}$ & 0.051 & 0.112 & 0.183 \\
\hline
\end{tabular}

Cols. 1 and 2: normalization on top firms. Col. 3: normalization on all sample. Standard errors in parentheses. *: significant at $10 \%$ level; $* *$ :significant at $5 \%$ level; ***:significant at $1 \%$ level 


\section{The Keynes+Schumpeter model}

How can one account, from a theoretical perspective, for the puzzle concerning the origin of the granular residual? In the rest of the paper, we will try to explain this fresh piece of empirical evidence employing the "Schumpeter meeting Keynes" AgentBased Model $(\mathrm{K}+\mathrm{S}$, cf. Dosi et al. 2015). The model is particularly suited for such theoretical venture as it sports both a Schumpeterian and a Keynesian engine, which allows it to jointly account for endogenous growth cum business fluctuations punctuated by major crises. Moreover, productivity and investment dynamics stem from the microeconomic decisions of heterogeneous, interacting firms. Finally, the model has shown to be able to reproduce a long list of microeconomic stylized facts (e.g. firm size and firm growth rate distributions, etc.) that are a pre-requisite for studying the granular origin of business cycles (more on that in Dosi et al. 2016a). Those microeconomic empirical regularities will be further detailed in Section 4.1. Below we describe the general features of the model, putting forward the microeconomic mechanisms, centered on productivity and investment, at the origin of the Schumpeterian and Keynesian macroeconomic dynamics.

The economy is composed of two industrial sectors, one in which $F_{1}$ firms (denoted by the subscript $i$ ) perform R\&D and produce heterogeneous machines, and one in which $F_{2}$ firms (denoted by the subscript $j$ ) buy those machines which are used to produce and sell a homogenous good. $L^{S}$ workers supply labour to the two sectors and use their income (either the wage or the unemployment subsidy) to consume the final good. Firms exit when they go bankrupt or their market share is null, and are replaced by new entrants. Firms' labour productivity evolves due to their innovation and imitation success in the first sector, and is linked to the quality of the machines they acquire through investment in the second sector. (Desired) investment by consumption-good firms depends on the confrontation of their production capacity and their expected demand, as well as the need for machine replacement. Those investment plans are then funded either by internal cash flow or external credit. In that sector, firm size (i.e. market share) is linked to firm competitiveness.

On the financial side of the economy, $B$ commercial banks (denoted by the subscript $k$ ) provide commercial credit to consumption-good firms and buy the sovereign bonds issued by the Government to finance its public debt. They are regulated by a Central Bank which sets the monetary and macroprudential policies in the economic system. In turn, government revenues come from taxes on firms' and banks' profits, and public expenses are related to debt cost, the payment of unemployment subsidies and the possible bailout of commercial banks in case of bank failure.

In the beginning of each simulation, firm characteristics are initialized at a common level. Within each subsequent period, a series of decisions are taken by the agents, which are then aggregated into macroeconomic variables (see below). Therefore, all types of heterogeneity in firm size, productivity, and investment patterns are emergent properties of the model. They are the result of idiosyncratic shocks (e.g. innovation success, incompatibility between sales and expected demand resulting in inventories) or come out of the interaction between individual agents (e.g. bankruptcy of a supplier, credit default negatively impacting a bank's balance sheet and resulting in higher credit constraints). 


\subsection{The timeline of events}

In any given time period $(t)$, the following microeconomic decisions take place in sequential order:

1. Policy variables (e.g. capital requirement, tax rate, Central Bank interest rate, etc.) are fixed.

2. Total credit notionally providable by the banks to their clients is determined.

3. Capital-good firms perform R\&D, trying to discover new products and more efficient production techniques and to imitate the technologies and the products of their competitors. They then signal their machines to consumption-good firms under conditions of imperfect information.

4. Consumption-good firms decide how much to produce and invest. If internal funds are not enough, firms borrow from their bank. If gross investment is positive, consumption-good firms choose their supplier and send their orders.

5. In both industries firms hire workers according to their production plans and start producing. Consumption-good firms may get external finance from banks to pay for production (i.e., to advance wages).

6. The Government determines the amount of unemployment subsidies to allocate.

7. An imperfectly competitive consumption-good market opens. The market shares of firms evolve according to their price competitiveness.

8. Firms in both sectors compute their profits. If profits are positive, firms pay back their loans and deposit their net savings, if any.

9. Banks compute their profits and net worth. If the latter is negative they fail and they are bailed out by the Government.

10. Entry and exit take places. In both sectors firms with near zero market shares or negative net liquid assets are eschewed from the two industries and replaced by new ones.

11. Machines ordered at the beginning of the period are delivered and become part of the capital stock at time $t+1$.

At the end of each time step, aggregate variables (e.g. GDP, investment, employment...) are computed, summing over the corresponding microeconomic variables.

\subsection{The capital-good, consumption-good and banking industries}

In what follows we focus on the mechanisms underlying the evolution of firms' productivity and investment in the two sectors, as well as the credit allocation process. More details are included in the Appendix as well as in Dosi et al. (2015).

\subsubsection{Productivity growth and the capital-good sector}

The source of productivity growth can be found in the capital-good industry, in which firms use labour (under constant returns to scale) to perform R\&D activities. R\&D leads to risky innovation and/or imitation, with the aim of improving both their process (i.e. their own productivity of labour, $B_{i}^{\tau}$ ) and their products (i.e. the productivity embedded in the machines they produce, and which will define that of 
the consumption-good firms who buy them, $A_{i}^{\tau}$ ). The innovation (and similarly, the imitation) process has two stages. The first stage defines whether a given firm of the capital-good industry innovates (imitates) or not. This probability endogenously evolves according to the amount of R\&D invested by the firm into innovation $\left(I N_{i}\right)$ or imitation $\left(I M_{i}\right)$, as it is a random draw from a Bernoulli distribution of parameter $\theta_{i}^{i n}(t)=1-e^{-\zeta_{1} I N_{i}(t)}$, with $\zeta_{1} \leqslant 1\left(\right.$ or $\theta_{i}^{i m}(t)=1-e^{-\zeta_{2} I M_{i}(t)}$, with $\left.\zeta_{2} \leqslant 1\right)$. Such amount is set according to a heuristic in each period, where total R\&D (for innovation and imitation) is a fraction $v \in[0,1]$ of past sales, and is further split between both activities according to the parameter $\xi \in[0,1]$. In the second stage, those firms selected to innovate (imitate) draw the value of their process and product technologies as follows:

$$
\begin{array}{ll}
A_{i}^{h}(t)=A_{i}(t)\left(1+x_{i}^{A}(t)\right), & h=i n, i m, \\
B_{i}^{h}(t)=B_{i}(t)\left(1+x_{i}^{B}(t)\right), & h=i n, i m,
\end{array}
$$

where $x_{i}^{A}$ and $x_{i}^{B}$ are two independent draws from a $\operatorname{Beta}\left(\alpha_{1}, \beta_{1}\right)$ distribution over the support $\left[\underline{x}_{1}, \bar{x}_{1}\right]^{10}$ with $\underline{x}_{1} \in[-1,0]$ and $\bar{x}_{1} \in[0,1]$. An innovation (imitation) is "successful" if it surpasses the current vintage (at time $\tau$ ) in terms of costs and performances, but it can also "fail". The choice of which machine is to be produced between the current $(\tau)$, the one resulting from innovation $(\mathrm{in})$ or from imitation $(\mathrm{im})$ is made as follows:

$$
\min \left[p_{i}^{h}(t)+b c^{h}\left(A_{i}^{h}(t)\right)\right], \quad h=\tau, i n, i m,
$$

where $b$ is a positive payback period parameter used by consumption-good firms to decide whether to scrap old machines or not (see Eq. 7 below).

They advertise their machines to a subset of half the consumption-good firms, who then compare the price and quality (i.e. here, productivity) of the suppliers they receive offers from. Prices of machines are defined as a fixed markup over unit cost.

\subsubsection{Desired investment and the consumption-good sector}

Consumption-good firms produce a homogenous good using labour and capital under constant returns to scale. They evaluate their expected demand using a simple heuristic, whereby expected demand is equal to the demand realized in the previous period. ${ }^{11}$ Based on their expectation, they define desired production and the desired level of inventories (set at 10\%). They then confront such plans (or desired capital stock $K_{j}^{d}$ ) with the actual capital stock in order to evaluate the need for expansionary investment:

$$
E I_{j}^{d}(t)=K_{j}^{d}(t)-K_{j}(t) .
$$

Note that this process is constrained by a maximum threshold as suggested by the empirical literature.

\footnotetext{
${ }^{10}$ The shape and support of the Beta distribution define the extent of technological opportunities available to firms (see also Dosi et al. 2010).

${ }^{11}$ Other forms of expectation rules and their impact on individual and aggregate performances are studied in Dosi et al. (2017a).
} 
Total desired investment also includes replacement investment, i.e. the scrapping of old (with age $>20$ periods) or obsolete machines. Obsolescence is evaluated by comparing the productivity - price trade-off of machines of different vintages $\tau$ :

$$
R S_{j}(t)=\left\{A_{i}^{\tau} \in \Xi_{j}(t): \frac{p^{*}(t)}{c\left(A_{i}^{\tau}(t)\right)-c^{*}(t)} \leq b\right\}
$$

where $p^{*}$ and $c^{*}$ are the price and unit cost of production of new machines.

The final step of the investment process is the funding of such investment plans. Firms first use their internal funds (their net worth) and, if necessary, can ask for costly external funding from their bank. The credit allocation process is explained at the end of this section.

In each period, consumption good firms update their price according to a variable markup on unit costs of production (see details in the Appendix). Given the heterogeneous price but homogeneous good, do all final-good consumers switch to the cheapest supplier? This is not the case because they have imperfect information regarding the available prices. Still, market shares are positively associated with consumption-good firms' competitiveness $\left(E_{j}\right)$, which reflects both their price and their amount of unfilled demand $\left(l_{j}\right)$ as inherited from the previous period:

$$
E_{j}(t)=-p_{j}(t)-l_{j}(t)
$$

where the unfilled demand $l_{j}(t)$ is the difference between actual demand and production of the period. A firm's market share is then driven by its relative competitiveness compared to the weighted average $(\bar{E}),{ }^{12}$ following a "quasi" replicator dynamics:

with $\chi=1$.

$$
f_{j}(t)=f_{j}(t-1)\left(1-\chi \frac{E_{j}(t)-\bar{E}(t)}{\bar{E}(t)}\right),
$$

\subsubsection{Credit allocation and the banking sector}

Each bank has a fixed portfolio of consumption-good firms as clients, to whom it can lend in each period. The number of clients per bank is heterogeneous, following a Pareto distribution of parameter paret $_{a}$. Note however that the size of each client evolves endogenously from the simulations. Similarly, banks' balance sheets evolve over time from the interaction with their clients, as loan losses affect bank profits and equity.

Banks' maximum supply of credit is computed in each period according to the (fixed) macroprudential framework (the minimum capital requirement $\tau^{b} \in[0,1]$ ), their equity $\left(N W_{k}^{b}\right)$ and financial fragility $\left(L e v_{k}\right.$, the accumulated bad debt):

$$
T C_{k}(t)=\frac{N W_{k}^{b}(t-1)}{\tau^{b}\left(1+\operatorname{Lev}_{k}(t-1)\right)},
$$

${ }^{12}$ It is computed using the market shares of the previous period: $\bar{E}(t)=\sum_{j=1}^{F_{2}} E_{j}(t) f_{j}(t-1)$. 
Banks then rank their clients in need for credit from "best" to "worst" according to their net worth to sales ratio in the previous period, and allocate the available credit in a pecking order basis until it is all exhausted. Credit cost is firm- and time-specific: it has a time-specific component which is based on the Central Bank interest rate $r_{t}$ (as driven by a Taylor rule targeting inflation), a bank markup component, and a firm-specific risk premium which is given by the firm's credit class (see details in the Appendix). Credit constraints endogenously emerge either due to supply constraints (the bank doesn't have enough credit to meet all its clients' needs) or to a maximum loan-to-value ratio. In such case, firms needs to reduce first their investment then their production plans according to available funds.

\subsubsection{End-of period dynamics: profits, exit and entry}

At the end of the period, all firms and banks pay taxes on their positive profits at the tax rate $t r$. Banks earn profits out of the loans they allocate as well as the government bonds they own (see Dosi et al. 2015 for more details about the evolution of banks' balance sheets). Consumption-good firms reimburse part of their debt (one third of total debt is reimbursed in each period). If firms' final net worth is negative or if they have (quasi) zero market share, they exit and are replaced by a new one.

In the capital and consumption good sectors, firms enter with a relatively low stock of liquid assets (and of capital in the latter sector) which is a (random) multiple ${ }^{13}$ of average incumbent size, following the empirical literature on firm entry (Caves 1998; Bartelsman et al. 2005). Capital-good firms' initial technology is drawn from a Beta distribution of parameters $\alpha_{2}, \beta_{2}$ and limited by the best available technology on the market.

Also banks can accumulate losses (in case of default by their clients, when they exit the market) and fail. Bankrupt banks are bailed out by the Government which provides new capital so that the bank remains solvent. More precisely, the net worth after bailout is a random multiple of the equity of the smallest bank, or the minimum level of capital needed to respect the macroprudential framework. Bailout expenses are added as a cost to the public budget (see Eq. 12 in the next section).

\subsection{Aggregate variables: private consumption and the public budget}

\subsubsection{Aggregate demand}

In this version of the $\mathrm{K}+\mathrm{S}$ model, the labour market is homogenous (see Dosi et al. $2017 \mathrm{~b}$ for a microfoundation of the labour market in the $\mathrm{K}+\mathrm{S}$ model). All workers earn the same wage $w$ which evolves over time according to the inflation gap, average productivity $(\overline{A B})$ and the unemployment rate:

$$
\frac{\Delta w_{(t)}}{w_{(t-1)}}=\pi^{T}+\psi_{1}\left(\pi_{(t-1)}-\pi^{T}\right)+\psi_{2} \frac{\Delta \overline{A B}_{(t)}}{\overline{A B}(t-1)}-\psi_{3} \frac{\Delta U_{(t)}}{U_{(t-1)}}
$$

\footnotetext{
${ }^{13}$ They draw a value from a uniform distribution between 0.1 and 0.9 .
} 
where $\psi_{1,2,3}>0$. There is a fixed labour supply, while labour demand depends on the firms' needs in every period. As a consequence, excess supply (i.e. involuntary unemployment) or excess demand (i.e. labour rationing) endogenously emerge. Aggregate demand is the sum of earnings of all workers (both active and unemployed) in each period, as we assume workers cannot save.

\subsubsection{The public budget}

The Government gathers taxes on firms' and banks' profits to fund unemployment subsidies (set as a multiple $\varphi \in[0,1]$ of the current wage rate, and aggregated to government expenses $G$ ), bank bailouts (Gbailout) and public debt costs (Debt ${ }^{\text {cost }}$ ). Public deficit is then computed as:

$$
\operatorname{Def}(t)=\operatorname{Debt}^{\cos t}(t)+\text { Gbailout }(t)+G(t)-\operatorname{Tax}(t) .
$$

The Government funds this deficit by issuing new bonds, bought by banks according to their size, using their net profits, or, if necessary, by the Central Bank. Public surpluses are used to reduce public debt.

\subsubsection{Macroeconomic variables}

In this bottom-up approach, both microeconomic (i.e. investment and productivity levels of firms) and macroeconomic outcomes can be observed and studied. Decisions by a multiplicity of heterogeneous, adaptive firms are summed to form macroeconomic aggregates (e.g. total GDP) and satisfy standard national account identities. In what follows we study the simulated microeconomic and macroeconomic data, first for validation purposes, and second we test the ability of the model to replicate the results presented in Section 2.

\section{The granular hypothesis: a theoretical interpretation}

The $\mathrm{K}+\mathrm{S}$ model can endogenously generate long-run growth characterized by business fluctuations and rare, deep crises. Moreover, the model is able to reproduce a wide range of macroeconomic stylized facts (e.g. relative volatilities and co-movements between the main macroeconomic variables, GDP growth rates distributions, etc.), as well as microeconomic regularities concerning the heterogeneity of firm and productivity dynamics (Dosi et al. 2016a). The latter are specifically important as they are strictly linked to the emergence of the granular hypothesis. For this reason, in this section we will first study more in detail the firm- and industrialdynamics emergent properties generated by the $\mathrm{K}+\mathrm{S}$ model (cf. Section 4.1). Then, we will employ the model to investigate the granular hypothesis (i.e. the impact of idiosyncratic firm shocks on aggregate growth) and the types of shocks that best explain GDP growth dynamics (Section 4.2). 


\subsection{Firm dynamics in the $\mathrm{K}+\mathrm{S}$ model}

Let us study whether the properties of firm demographics and dynamics (i.e. firm size and firm growth) are in line with the empirical evidence, as well as with the assumptions imposed by the granular hypothesis. Note that none of the regularities presented below was imposed ex ante, but they are properties emerging out of the disequilibrium interactions among heterogeneous firms. The empirical evidence (Sutton 1997; Lee et al. 1998; Bottazzi and Secchi 2003a, b; Bottazzi et al. 2007; Dosi 2007) suggests that: i) firm size distributions are right-skewed and well-approximated by power-law densities of exponent 1; (ii) firm growth-rate distributions are fat-tailed and well approximated by a Laplace distribution at any scale of aggregation; ${ }^{14}$ iii) firm growth is independent from its size (aka Gibrat's law); ${ }^{15}$ and iv) the variance of firm growth rates decays inversely with firm size. ${ }^{16}$

In a first step we consider the properties of the cross-sectional distributions of firm demographics. In tune with the empirical evidence, firm size distributions generated by the $\mathrm{K}+\mathrm{S}$ model are well approximated by power-law densities of exponent 1 (see Fig. 3). At the same time, model-generated firm growth rates are Laplace distributed (cf. Fig. 4). ${ }^{17}$

As a second step, we also test firm size dynamics. A benchmark model in that respect is represented by the so-called Gibrat's law (Gibrat 1931; Sutton 1997; Dosi 2007), which postulates the independence of firm growth rates from its size:

$$
s_{i}(t)=\alpha+\theta s_{i}(t-1)+\epsilon_{i}(t),
$$

where $s_{i}$ is the $\log$ of size of firm $i$ and $\alpha$ is a sector-wide or economy-wide component of growth. Gibrat's law in its strong form suggests that $\theta=1, \forall i$, and $\epsilon_{i}(t)$ is an independent, identically and normally distributed random variable with zero mean. The first proposition is also known as "law of proportionate effects" (see Dosi 2007) and it basically states the independence of a firm growth from its size. The second statement implies that the distribution of firm size and firm growth rates should respectively be log-normal and Gaussian.

We study whether the "law of proportionate effects" is accounted by the $\mathrm{K}+\mathrm{S}$ model estimating Eq. 13 using our simulated microeconomic data. We pool firm size information across different Monte-Carlo simulations. The results are spelled out in Table 3. Remarkably, the estimated slope of the regression (coefficient $\theta$ ) turns out

\footnotetext{
${ }^{14}$ That would actually be an understatement, as Williams et al. (2015) have found that the distribution of firm growth rates is better approximated by the heavier-tailed Cauchy distribution.

${ }^{15}$ One important exception concerns the growth dynamics of small firms, that appear to be negatively correlated with size (see Dosi 2007 for a discussion).

${ }^{16}$ See Dosi et al. (2016b) for an industrial-dynamics agent-based model able to jointly explain the emergence of such regularities.

${ }^{17}$ The estimation of the size distribution was performed by using the "power law package" discussed in Clauset et al. (2009). For firm growth rates data, we estimated an exponential-power distribution, which encompasses as a special case both the normal distribution and the Laplace (see Bottazzi and Secchi 2006; Fagiolo et al. 2008). The estimated coefficient of the shape parameter of the distribution was not statistically different from one, thus indicating that the Laplace distribution provides indeed a good approximation of the distribution of firm growth rates in the $\mathrm{K}+\mathrm{S}$ model.
} 


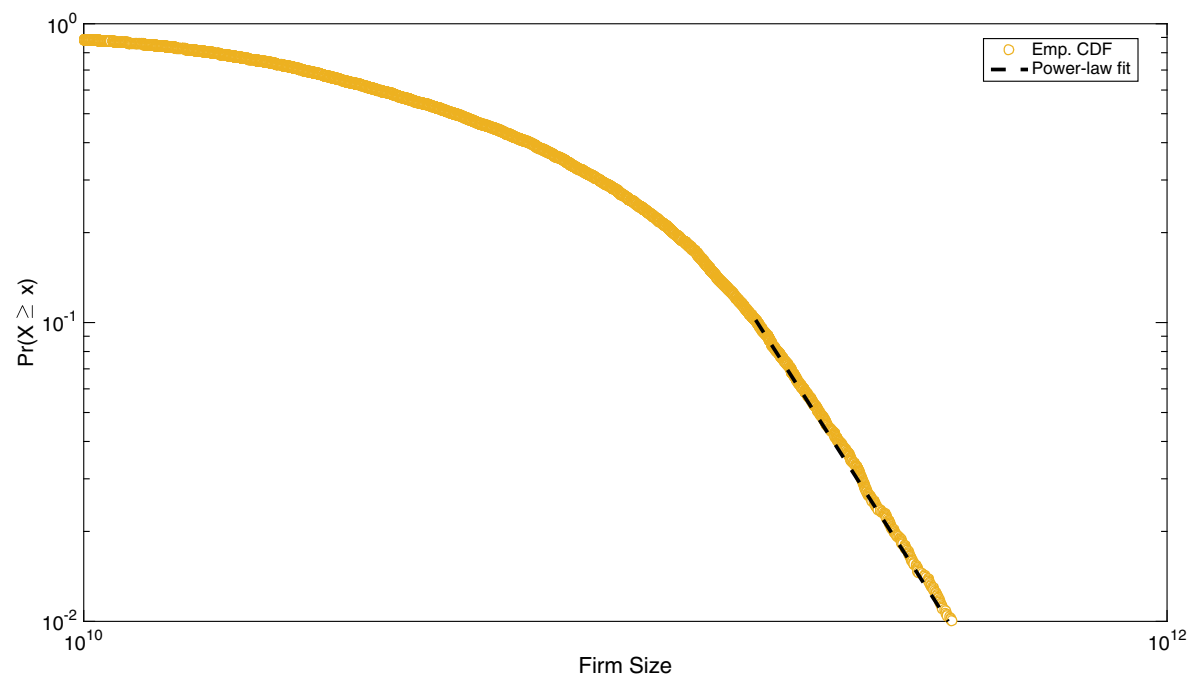

Fig. 3 Firm size distribution and power-law fit. Firm size data were generated by the K+S model in the baseline scenario and pooled across 50 Monte-Carlo simulations

not to be statistically different from one, in line with the empirical evidence (see e.g. Bottazzi and Secchi 2003a, b; Dosi 2007 among others), and suggesting that expected average firm growth rates are independent from firm size. Figure 5 captures this result by displaying a scatter plot of the logarithm of firm size at two consecutive periods together with the fitted line from the Gibrat's regression.

We now consider the higher moments of firm growth dynamics and relate the standard deviation of firm growth with firm size. For this analysis, we follow the same procedure as in Amaral et al. (1997) and Bottazzi and Secchi (2006). We take

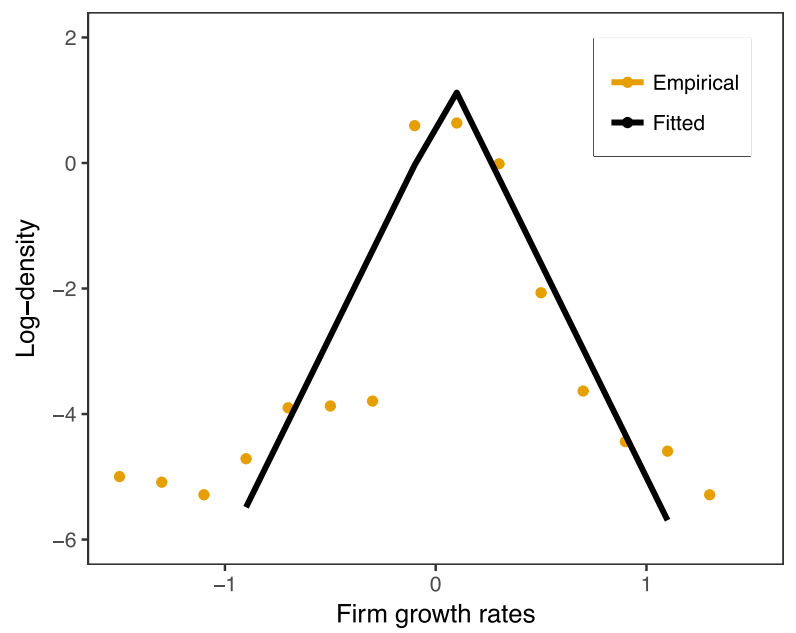

Fig. 4 Firm growth rate density and exponential-power (EP) fit. Firm growth rate data were generated by the $\mathrm{K}+\mathrm{S}$ model in the baseline scenario and pooled across 50 Monte-Carlo simulations 
Table 3 Gibrat's law regression on simulated data

\begin{tabular}{ll}
\hline Gibrat's law & \\
\hline Dep. var: & Size $s_{i}(t)$ \\
\hline$\alpha$ & $0.387 * * *$ \\
& $(0.050)$ \\
Size $s_{i}(t-1)$ & $0.988^{* * *}$ \\
& $(0.002)$ \\
$N$ & 8889 \\
$R^{2}$ & 0.963 \\
\hline
\end{tabular}

Standard errors in parentheses.

*: significant at $10 \%$ level;

$* *$ :significant at $5 \%$ level;

$* * *$ :significant at $1 \%$ level

the firm size data resulting from the $\mathrm{K}+\mathrm{S}$ model, pooled across $\mathrm{MC}=50$ simulations. We then bin the data according to percentiles of the firm size distribution. Next, we compute the standard deviation of firm growth rates and the average size within each bin. Table 4 reports the results of the OLS regression of the standard deviation $\left(\sigma_{i}\right)$, obtained according to the foregoing procedure, on the logarithm of average size across bins $\left(s_{i}\right)$. More formally, we estimate the following relationship:

$$
\sigma_{i}=\alpha+\theta s_{i}+\epsilon_{i}
$$

The results show that the estimated slope is negative and statistically different from zero, thus confirming the presence of a negative relation between firm growth volatility and their size, as found in real data. Figure 6 provides a visualization of the estimated relationship, as well as the goodness of fit of the regression model in Eq. 14.

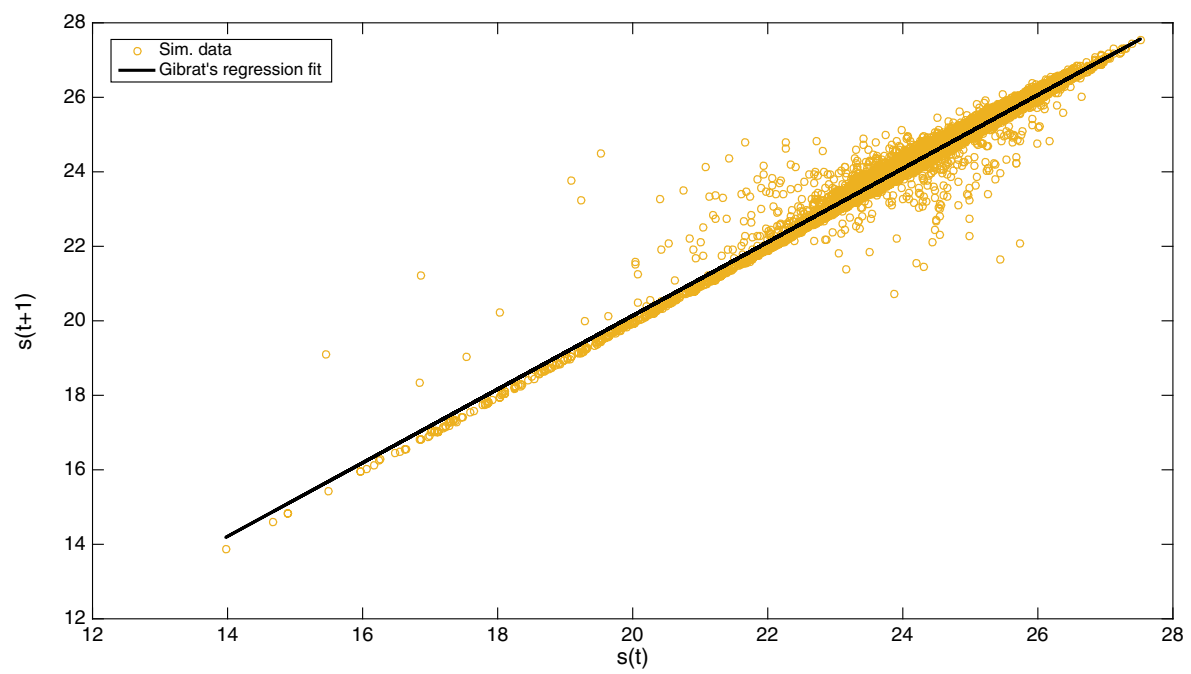

Fig. 5 Gibrat's law. Scatter plot of the logarithm of firm size at two consecutive periods, $s(t), s(t-$ $1)$, together with Gibrat's regression fit. Firm size data are generated by the $\mathrm{K}+\mathrm{S}$ model in the baseline scenario and pooled across 50 Monte-Carlo simulations 
Table 4 Volatility-size regression on simulated data
Volatility-size relation

Dep. var:

Std. dev. of firm growth $\sigma_{i}$

$\alpha \quad 1.885 * * *$

Size $s_{i}$

(0.007)

Standard errors in parentheses.

*: significant at $10 \%$ level;

$* *$ :significant at $5 \%$ level;

$* * *$ :significant at $1 \%$ level
$N$
$R^{2}$
0.522

\subsection{Emergent granularity in the $\mathrm{K}+\mathrm{S}$ model}

The previous section showed that the $\mathrm{K}+\mathrm{S}$ model fares very well in replicating the main empirical properties of firm dynamics. In particular, the fact that the distribution of firm size has a power-law shape with exponent 1 (especially in the tail) opens the way to the possibility that business cycles can have a granular origin, that is fluctuations in GDP growth may steam from shocks hitting the largest firms in the economy. As the empirical analysis in Section 2 suggests the lack of robustness of the original, productivity, supply-side granular hypothesis of Gabaix (2011), and the possible relevance of an investment, demand-side residual, we will try to shed light on such puzzles employing the simulation results generated by the $\mathrm{K}+\mathrm{S}$ model.

We start by inspecting the share of GDP of the largest firms in the simulated data. Figure 7 shows the evolution of such shares for respectively the top 5\%, 12.5\%

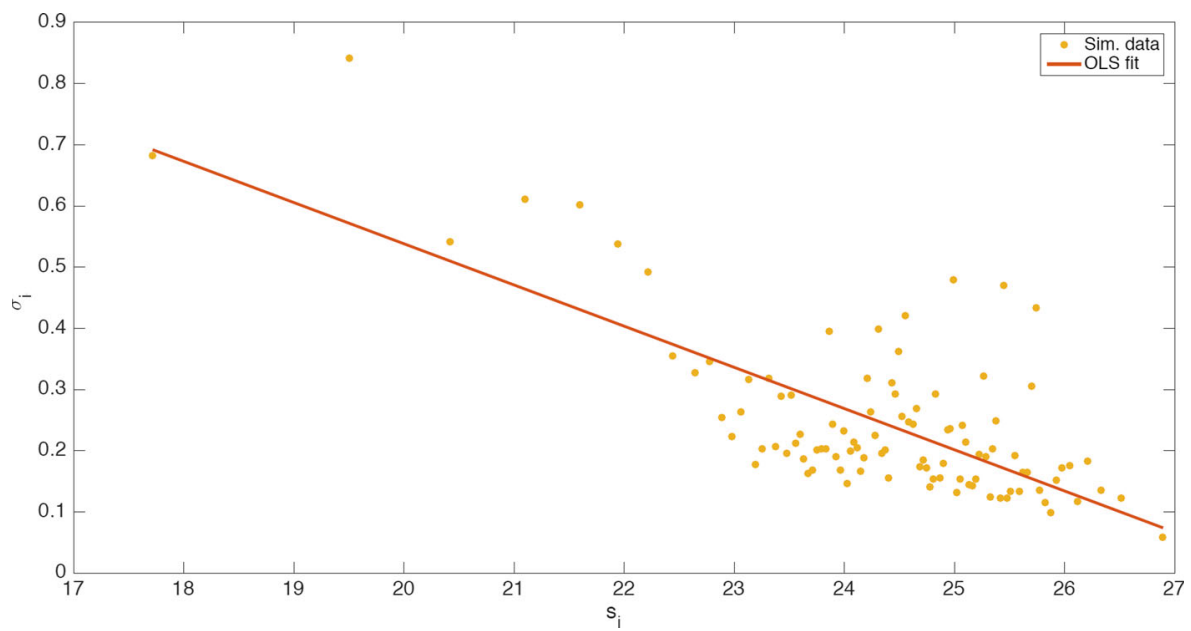

Fig. 6 Relation between firm growth rates volatility and size. The red line was generated out of the OLS estimation of the model in Eq. 14. Firm size and growth rates data were generated by the $\mathrm{K}+\mathrm{S}$ model in the baseline scenario and pooled across 50 Monte-Carlo simulations. The standard deviation of growth rates $\sigma_{i}$ was computed with growth data according to firm size percentiles 


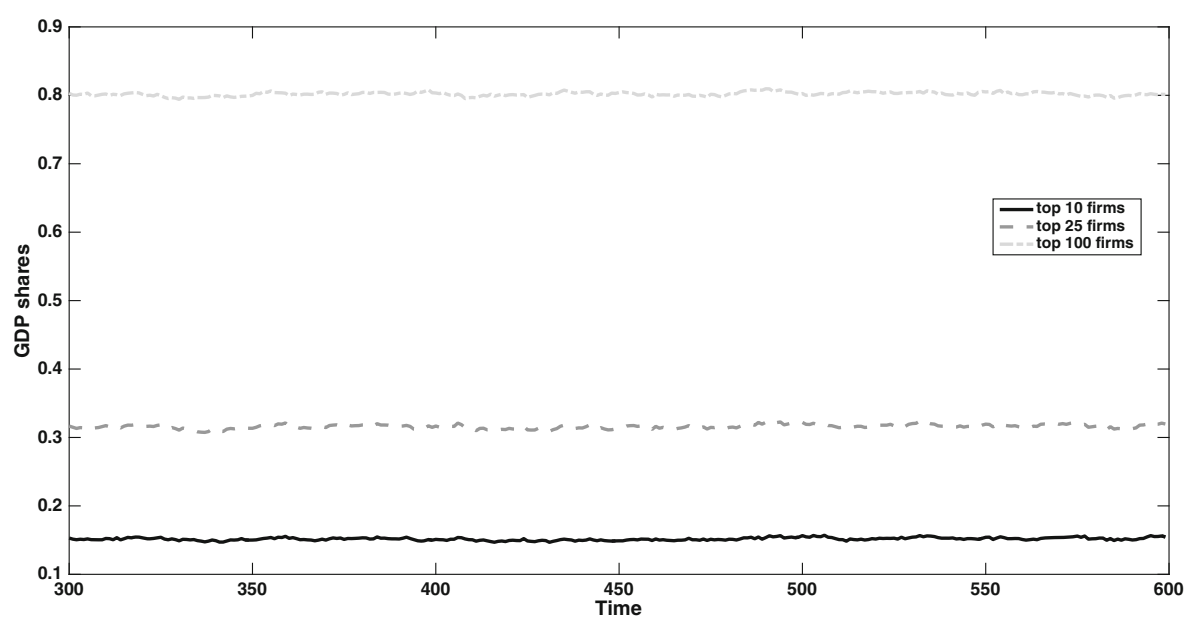

Fig. 7 Evolution of GDP shares of groups of different groups of large firms in the consumption-good sector of the $\mathrm{K}+\mathrm{S}$ model

and $50 \%$ firms in the manufacturing sector. ${ }^{18}$ As the consumption-good sector has a population of 200 firms, this corresponds to the top 10, 25 and 100 firms. The shares of the largest firms are very stable over time. In addition, the top 25 firms account for more than one third of total production. This is a similar share accounted by top 100 U.S. firms in COMPUSTAT data (see also Gabaix 2011). For this reason, our analysis will focus on the top 25 firms in the simulated data.

We compute the granular residuals among the top 25 firms using labour productivity and investment growth rates. More precisely, the residual is computed as in Eq. 1 with $\mathrm{K}=25$ and $\mathrm{Q}=200$ (the growth rates are depurated from the average in the entire consumption-good sector). In order to compare the results with the empirical ones, we compute a version of the residuals à la Gabaix, with winsorizing at $20 \%$, and a version without such cleaning. In addition, the simulated data displays significant high-frequency noise. To eliminate it we filter both the GDP growth rate and the granular residuals applying the Christiano-Fitzgerald bandpass filter. This allows us to extract the business cycles components of all the variables considered in the regressions on simulated data.

In Table 5 we report results of the regressions performed on the simulated data. We find that the $\mathrm{K}+\mathrm{S}$ model successfully reproduces the empirical patterns described in Section 2: the productivity granular residual is never significant (with and without winsorizing), whereas the investment growth residual significantly contributes to explain GDP growth, especially when data are not winsorized. This outcome, together with the evidence about Zipf-law firm size distributions (cf. Section 4.1) shows that the $\mathrm{K}+\mathrm{S}$ model can generate, as an emergent property, an economy with granular fluctuations. Moreover, simulation results confirm that such

\footnotetext{
${ }^{18}$ To simplify our analysis, we consider only the consumption-good sector which accounts for $90 \%$ of GDP in the simulations.
} 
Table 5 Regressions on simulated data

\begin{tabular}{|c|c|c|c|c|}
\hline \multirow{3}{*}{ Dep. var: } & \multirow{2}{*}{\multicolumn{2}{|c|}{$\begin{array}{l}\text { Productivity growth residuals } \\
\text { GDP growth }\end{array}$}} & \multirow{2}{*}{\multicolumn{2}{|c|}{ Investment growth residuals }} \\
\hline & & & & \\
\hline & $\begin{array}{l}\text { Winsorizing } \\
\text { (1) }\end{array}$ & $\begin{array}{l}\text { Not winsorizing } \\
\text { (2) }\end{array}$ & $\begin{array}{l}\text { Winsorizing } \\
\text { (3) }\end{array}$ & $\begin{array}{l}\text { Not winsorizing } \\
\text { (4) }\end{array}$ \\
\hline (Intercept) & $\begin{array}{l}0.030 * * * \\
(0.000)\end{array}$ & $\begin{array}{l}0.030 * * * \\
(0.000)\end{array}$ & $\begin{array}{l}0.030 * * * \\
(0.000)\end{array}$ & $\begin{array}{l}0.030 * * * \\
(0.000)\end{array}$ \\
\hline$\Gamma_{i}(t)$ & $\begin{array}{l}0.182 \\
(0.660)\end{array}$ & $\begin{array}{l}0.379 \\
(0.543)\end{array}$ & $\begin{array}{l}0.069 \\
(0.051)\end{array}$ & $\begin{array}{l}0.057 * * \\
(0.027)\end{array}$ \\
\hline$\Gamma_{i}(t-1)$ & $\begin{array}{l}-0.258 \\
(1.034)\end{array}$ & $\begin{array}{l}-0.547 \\
(0.850)\end{array}$ & $\begin{array}{l}-0.105 \\
(0.080)\end{array}$ & $\begin{array}{l}-0.080 * * \\
(0.040)\end{array}$ \\
\hline$\Gamma_{i}(t-2)$ & $\begin{array}{l}0.177 \\
(0.661)\end{array}$ & $\begin{array}{l}0.380 \\
(0.543)\end{array}$ & $\begin{array}{l}0.073 \\
(0.051)\end{array}$ & $\begin{array}{l}0.046 * \\
(0.027)\end{array}$ \\
\hline$g_{G D P}(t-1)$ & $\begin{array}{l}1.496 * * * \\
(0.030)\end{array}$ & $\begin{array}{l}1.495 * * * \\
(0.030)\end{array}$ & $\begin{array}{l}1.493 * * * \\
(0.030)\end{array}$ & $\begin{array}{l}1.498 * * * \\
(0.031)\end{array}$ \\
\hline$g_{G D P}(t-2)$ & $\begin{array}{l}-0.918 * * * \\
(0.030)\end{array}$ & $\begin{array}{l}-0.919 * * * \\
(0.030)\end{array}$ & $\begin{array}{l}-0.918 * * * \\
(0.030)\end{array}$ & $\begin{array}{l}-0.917 * * * \\
(0.030)\end{array}$ \\
\hline $\mathrm{N}$ & 14850 & 14850 & 14850 & 14850 \\
\hline$R^{2}$ & 0.151 & 0.151 & 0.151 & 0.151 \\
\hline
\end{tabular}

Granular residual calculated on top 25 firms in the $\mathrm{K}+\mathrm{S}$ model. Data were pooled across Monte-Carlo, $\mathrm{MC}=50$ simulations. Standard errors in parentheses. *: significant at $10 \%$ level; **:significant at $5 \%$ level; $* * *$ :significant at $1 \%$ level

fluctuations have a Keynesian origin, possibly linked to the coordination failures arising from the out-of-equilibrium interactions of heterogeneous firms in the capital and consumption-good markets.

\section{Concluding remarks}

In this work we have investigated the granular origins of aggregate fluctuations from both an empirical and theoretical perspectives. At the empirical level, we have replicated the work of Gabaix (2011) employing the COMPUSTAT database to compute a granular residual considering the labour productivity growth of the largest US firms. We have also considered another residual considering firms' investment instead of productivity. The productivity growth residual is coherent with a Real Business Cycle (RBC) interpretation of business cycles, while the investment growth residual is in tune with a demand-side, Keynesian perspective.

We found that the empirical results on the granularity hypothesis are not very robust. The productivity growth residual largely loses power when one does not winsorize the data as in Gabaix (2011) to remove possible outliers. On the contrary, the investment granular residual has a much higher explanatory power. 
We have then employed the Keynes+Schumpeter $(\mathrm{K}+\mathrm{S})$ family of models (Dosi et al. 2010, 2013, 2015, 2017b) to shed further light on the sources of the granular residuals. The agent-based model is particularly suited for such an analysis as it sports both a Schumpeterian and a Keynesian engine which lead to the emergence of endogenous growth and business cycles.

At the microeconomic level, we find that the $\mathrm{K}+\mathrm{S}$ model can jointly account for the main stylized facts of firm dynamics (e.g. Zipf-law firm size distributions, Laplace firm growth-rate distributions, Gibrat's law, etc.). Moreover, in line with the empirical evidence, the model suggests that the investment granular residual is more important than the productivity one in explaining aggregate GDP fluctuations. Our simulation results show that granular fluctuations - as well as all the main properties of firm dynamics - can be generated as the result of disequilibrium interactions among heterogeneous firms. Moreover, both our empirical and theoretical results suggest a Keynesian demand-side origin of aggregate fluctuation vis-à-vis a supply-side RBC one.

Acknowledgments We are grateful to participants of the Computing in Economics and Finance conference in Milan (2018), Mattia Guerini, Simone Alfarano and one referee for comments and discussions. All usual disclaimers apply.

Compliance with Ethical Standards The authors gratefully acknowledge the financial support of the Horizon 2020 Framework Program of the European Union under grant agreement no 649186, ISIGrowth (Innovation-Fuelled, Sustainable, Inclusive Growth).

Conflict of interests The authors declare that they have no conflict of interest.

Open Access This article is distributed under the terms of the Creative Commons Attribution 4.0 International License (http://creativecommons.org/licenses/by/4.0/), which permits unrestricted use, distribution, and reproduction in any medium, provided you give appropriate credit to the original author(s) and the source, provide a link to the Creative Commons license, and indicate if changes were made.

\section{Appendix: The model: additional elements}

\section{Consumption good firms' markup dynamics}

Consumption-good firms' price is chosen by applying a variable mark-up $\left(\mu_{j}\right)$ on unit costs of production $\left(c_{j}\right)$ :

$$
p_{j}(t)=\left(1+\mu_{j}(t)\right) c_{j}(t) .
$$

where the unit cost at the firm level $c_{j}(t)$ is the average over all their current machines.

The variable mark-up is adjusted with respect to the evolution of firms' market shares $\left(f_{j}\right)$, where market share expansion allows firms to apply a higher mark-up: ${ }^{19}$

with $v=0.01$.

$$
\mu_{j}(t)=\mu_{j}(t-1)\left(1+v \frac{f_{j}(t-1)-f_{j}(t-2)}{f_{j}(t-2)}\right),
$$

\footnotetext{
${ }^{19}$ As based on "customer market" models.
} 


\section{Interest rates}

The Taylor rule is as follows:

$$
r_{(t)}=r^{T}+\gamma_{\pi}\left(\pi_{(t)}-\pi^{T}\right), \quad \gamma_{\pi}>1
$$

where $\pi_{t}$ is the inflation rate of the period and $r^{T}, \pi^{T}$ are the target interest and inflation rates respectively.

The firm-specific component of loan interest rates (or risk premium) depends on their credit class, itself based on their position in the credit ranking. Firms can be

Table 6 Parameters

\begin{tabular}{lll}
\hline Description & Symbol & Value
\end{tabular}

Benchmark parameters

Montecarlo replications

Time sample

$M C \quad 50$

Number of firms in capital-good industry

$T$

$F_{1} \quad 50$

Number of firms in consumption-good industry

$F_{2}$

Number of banks

$B$

Capital-good firms' mark-up

Consumption-good firm initial mark-up

$\mu$

$\bar{\mu}_{0}$

Wage setting $\triangle \overline{A B}$ weight

Wage setting $\Delta c p i$ weight

$\psi_{1}$

$\psi_{2}$

50

Wage setting $\Delta U$ weight

Banks deposits interest rate

Bond interest rate mark-down

Loan interest rate mark-up

Bank capital adequacy rate

Shape parameter of bank client distribution

Scaling parameter for interest rate cost

R\&D investment propensity

$\mathrm{R} \& \mathrm{D}$ allocation to innovative search

Firm search capabilities parameters

Beta distribution parameters (innovation process)

$\psi$

$r^{D}$

600

50

200

10

0.04

0.20

1

0.05

0.05

$\mu^{\text {bonds }} \quad-0.33$

$\mu^{\text {deb }} \quad 0.30$

$\begin{array}{ll}\tau^{b} & 0.08\end{array}$

pareto $_{a} \quad 0.08$

$k_{\text {const }} \quad 0.10$

$v \quad 0.04$

$\xi \quad 0.50$

$\zeta_{1,2} \quad 0.30$

$\left(\alpha_{1}, \beta_{1}\right)$

Beta distribution support (innovation process)

$\left[\underline{x}_{1}, \bar{x}_{1}\right]$

Mark-up coefficient

Competitiveness weights

Policy experiment parameters

Inflation adjustment parameter $\left(T R_{\pi}, T R_{\pi, U}\right)$

Target interest rate

$\begin{array}{ll}\gamma_{\pi} & 1.10 \\ r^{T} & 0.025 \\ \pi^{T} & 0.02 \\ t r & 0.10 \\ \varphi & 0.40\end{array}$


assigned to one of the four credit classes ( $q=1,2,3,4$ - from best to worst) in every period, which corresponds to the following loan rate:

$$
r_{j,(t)}^{d e b}=r_{(t)}^{d e b}\left(1+(q-1) k_{\text {const }}\right)
$$

with $\mu^{d e b}>0$ and $k_{\text {const }}$ a scaling parameter. Firms' deposits are rewarded at the rate $r_{(t)}^{D}$, banks' reserves at the Central Bank yield the reserves rate $r_{(t)}^{r e s}$, and government bonds pay an interest rate $r_{(t)}^{\text {bonds }}=\left(1+\mu^{\text {bonds }}\right) r_{(t)}$, with $-1<\mu^{\text {bonds }}<0$. The different interest rates are set so that $r_{(t)}^{D} \leq r_{(t)}^{r e s} \leq r_{(t)}^{\text {bonds }} \leq r \leq r_{(t)}^{\text {deb }} \cdot{ }^{20}$

\section{References}

Amaral LAN, Buldyrev SV, Havlin S, Salinger MA, Stanley HE, Stanley MH (1997) Scaling behavior in economics: the problem of quantifying company growth. Physica A 244:1-24

Arroyo OB, Alfarano S (2017) Granularity of the business cycle fluctuations: the Spanish case. Economía Coyuntural, Revista de Temas de Perspectivas y Coyuntura 2(1):31-58

Ascari G, Fagiolo G, Roventini A (2015) Fat-tail distributions and business-cycle models. Macroecon Dyn 19:465-476. https://doi.org/10.1017/S1365100513000473. http://journals.cambridge.org/article S1365100513000473

Axtell RL (2001) Zipf distribution of us firm sizes. Science 293:1818-1820

Bartelsman EJ, Scarpetta S, Schivardi F (2005) Comparative analysis of firm demographics and survival: micro-level evidence for the oecd countries. Ind Corp Chang 14:365-391

Bottazzi G, Secchi A (2003a) Common properties and sectoral specificities in the dynamics of US manufacturing firms. Rev Ind Organ 23:217-232

Bottazzi G, Secchi A (2003b) Why are distribution of firm growth rates tent-shaped? Econ Lett 80:415420

Bottazzi G, Secchi A (2006) Explaining the distribution of firm growth rates. RAND J Econ 37:235-256

Bottazzi G, Cefis E, Dosi G, Secchi A (2007) Invariances and diversities in the patterns of industrial evolution: some evidence from italian manufacturing industries. Small Bus Econ 29(1-2):137-159

Bottazzi G, Li L, Secchi A et al (2017) Aggregate fluctuations and the distribution of firm growth rates. LEM Working Paper Series 2017/24' Sant'Anna School of Advanced Studies. Pisa, Italy

Carvalho V, Grassi B (2015) Large firm dynamics and the business cycle. Economics Working Papers, no 1481, Department of Economics and Business, Universitat Pompeu Fabra

Castaldi C, Dosi G (2009) The patterns of output growth of firms and countries: scale invariances and scale specificities. Empir Econ 37(3):475-495

Caves R (1998) Industrial organization and new findings on the turnover and mobility of firms. J Econ Lit 36:1947-1982

Clauset A, Shalizi CR, Newman ME (2009) Power-law distributions in empirical data. SIAM Rev 51(4):661-703

Clementi GL, Palazzo B (2016) Entry, exit, firm dynamics, and aggregate fluctuations. American Economic Journal: Macroeconomics 8(3):1-41

Di Giovanni J, Levchenko AA (2012) Country size, international trade, and aggregate fluctuations in granular economies. J Polit Econ 120(6):1083-1132

Di Giovanni J, Levchenko AA, Rancière R (2011) Power laws in firm size and openness to trade: measurement and implications. J Int Econ 85(1):42-52

Di Giovanni J, Levchenko AA, Méjean I (2014) Firms, destinations, and aggregate fluctuations. Econometrica 82(4):1303-1340

\footnotetext{
${ }^{20}$ Those interest rates are set with a mark-down or a mark-up up on the contemporaneous central bank interest rate $r_{t}$ such that $r_{t}^{D}=0 ; r_{t}^{\text {res }}=0.66 r_{t} ; r_{t}^{\text {bonds }}=r_{t} ; r_{t}^{\text {deb }}=1.3 r_{t}$.
} 
Dosi G (2007) Statistical regularities in the evolution of industries. A guide through some evidence and challenges for the theory. In: Malerba F, Brusoni S (eds) Perspectives on innovation. Cambridge University Press, Cambridge, pp 153-186

Dosi G, Fagiolo G, Roventini A (2010) Schumpeter meeting keynes, a policy-friendly model of endogenous growth and business cycles. J Econ Dyn Control 34:1748-1767

Dosi G, Fagiolo G, Napoletano M, Roventini A (2013) Income distribution, credit and fiscal policies in an agent-based keynesian model. J Econ Dyn Control 37:1598-1625

Dosi G, Fagiolo G, Napoletano M, Roventini A, Treibich T (2015) Fiscal and monetary policies in complex evolving economies. J Econ Dyn Control 52:166-189

Dosi G, Napoletano M, Roventini A, Treibich T (2016a) Micro and macro policies in keynes+schumpeter evolutionary models. J Evol Econ 27:63-90

Dosi G, Pereira MC, Virgillito ME (2016b) The footprint of evolutionary processes of learning and selection upon the statistical properties of industrial dynamics. Ind Corp Chang 26(2):187-210

Dosi G, Napoletano M, Roventini A, Stiglitz J, Treibich T (2017a) Rational heuristics? Expectations and behaviors in evolving economies with heterogeneous interacting agents. LEM Working Paper Series 2017/31, Sant'Anna School of Advanced Studies

Dosi G, Pereira MC, Roventini A, Virgillito ME (2017b) When more flexibility yields more fragility: the microfoundations of keynesian aggregate unemployment. J Econ Dyn Control 91:162-186

Fagiolo G, Roventini A (2012) Macroeconomic policy in agent-based and dsge models. Revue de l'OFCE 124(5):67-116

Fagiolo G, Roventini A (2017) Macroeconomic policy in DSGE and agent-based models redux: new developments and challenges ahead. J Artif Soc Social Simul 20(1):1

Fagiolo G, Napoletano M, Roventini A (2008) Are output growth-rate distributions fat-tailed? Some evidence from oecd countries. J Appl Econom 23:639-669

Gabaix X (2011) The granular origins of aggregate fluctuations. Econometrica 79(3):733-772

Gibrat R (1931) Les inégalités Economiques. Librairie du Recueil Sirey, Paris

Ijiri Y, Simon HA (1977) Skew distributions and the sizes of business firms. North-Holland, Amsterdam

Lee Y, Amaral LAN, Canning D, Meyer M, Stanley HE (1998) Universal features in the growth dynamics of complex organizations. Phys Rev Lett 81:3275-3278

Sutton J (1997) Gibrat's legacy. J Econ Lit 35:40-59

Williams MA, Pinto BP, Park D (2015) Global evidence on the distribution of firm growth rates. Physica A: Statistical Mechanics and its Applications 432:102-107 